\title{
Core RxLR Effectors in Phytopathogenic oomycetes: A promising way to breeding for durable resistance in plants?
}

Jane Chepsergon, ${ }^{1}$ Thabiso E. Motaung, ${ }^{1}$ Lucy Novungayo Moleleki ${ }^{1 *}$

${ }^{1}$ Department of Biochemistry, Genetics and Microbiology, Forestry and Agricultural Biotechnology, University of Pretoria, Pretoria, Gauteng, South Africa

*Correspondence: Lucy Novungayo Moleleki, lucy.moleleki@fabi.up.ac.za

\begin{abstract}
Phytopathogenic oomycetes are known to infect a host plant successfully due to their ability to secrete a set of protein effectors. Of interest to many researchers are effectors with the N-terminal RxLR motif (Arginine-any amino acid-LeucineArginine). Owing to the genome sequencing, we can now comprehend the high level of diversity among oomycete effectors, and similarly, their conservation within and among species core RxLR effectors (CREs). Currently, there are a couple of putative CREs that have been identified in oomycetes. Functional characterization of these CREs propose their virulence role with the potential of targeting central cellular processes that are conserved across diverse plant species. This could be harnessed in engineering plants for broad-spectrum and durable resistance.
\end{abstract}

\section{Keywords: oomycetes; effectors; durable-resistance; virulence}

\section{Introduction}

The oomycetes comprise of a group of successful filamentous microorganisms that threaten not only the global food security but also the natural ecosystems (Thines \& Kamoun, 2010); (McGowan \& Fitzpatrick, 2020). Most notorious among oomycete species is the hemibitrophs Phytopthora, also known as "the plant destroyers" (Haas et al., 2009; Hardham, 2005; Rizzo et al., 2005; Tyler, 2007). Another group of plant devastating oomycete species is the obligate biotrophs including downy mildews, Bremia lactucae and Plasmopara viticola (Dussert et al., 2019; Fletcher et al., 2019). The 
success of these pathogens is attributed to their ability to secrete an arsenal of effectors with the RxLR motif of Arginine-any amino acid-Leucine-Arginine (Haas et al., 2009; Jiang et al., 2008). It was previously postulated that RxLR-containing effectors represent a rapidly evolving class of effectors that are associated with the biotrophic phase of oomycetes infection (Schornack et al., 2010). This could be true since most of these effectors have been shown to be highly expressed at the early infection stage and are required for suppression of host immunity (Q. Wang et al., 2011; Yin et al., 2017; Zheng et al., 2014). In addition, necrotrophic oomycetes, precisely Pythium species, were previously thought to be lacking any RXLRencoding genes (Adhikari et al., 2013; Lévesque et al., 2010; Rujirawat et al., 2018). Surprisingly,(Ai et al., 2020) predicted a total of 359 putative RXLR effectors from nine Pythium species. Therefore, it is possible that RxLRs in oomycetes are a superfamily which suggests that they could be sharing a common ancestor.

Owing to the tremendous advancements in next-generation sequencing technologies, several genomes of phytopathogenic oomycetes have been sequenced (McGowan \& Fitzpatrick, 2020). This allows a detailed analysis of existing trenchwarfare scenario between pathogens and host plants accompanied by secretion of RxLR effectors. To date, there are several reviews on the role of RxLRs in pathogenhost interaction (Anderson et al., 2015; Birch et al., 2009; Boevink et al., 2020; Chepsergon et al., 2020; Krishnan et al., 2019; J. Wang et al., 2019; Whisson et al., 2016). Because of genome sequencing, we can now comprehend the high level of diversity among oomycete effectors, and similarly, their conservation within and among species also known as "core effectors". The concept of core effectors has been well documented in bacteria (Baltrus et al., 2011; Bart et al., 2012; Dangl et al., 2013) and fungi (De Jonge et al., 2010; Hemetsberger et al., 2015; Marshall et al., 2011; Mentlak et al., 2012; Saitoh et al., 2012). In oomycetes however, this concept is recent and has not been precisely documented. Therefore, this review presents the concept of conserved/core effectors in plant pathogens, identification of core RxLR effectors 
(CREs) in oomycetes, their role in virulence as well as their potential application in breeding for durable resistance.

\section{What are core effectors?}

The success of most pathogens has been attributed to their ability to secrete effectors that enhance the virulence of the pathogen as well as alter the physiology of the host plant for enhanced disease development (Zhang \& Coaker, 2017). Pathogens employ effectors to escape plant immunity response and this explains why integrated resistance in plants is short-lived.

Studies have revealed that pathogens can express an arsenal of effectors that are diverse across the population of any pathogen species (Dangl et al., 2013; Raffaele et al., 2010). This has been attributed to the physical location of these effectors which is the gene-sparse, transposon-rich regions of the pathogen genome (Haas et al., 2009; Raffaele \& Kamoun, 2012). In addition, variation of effector genes has been associated with either intragenic recombination or intergenic recombination (Yang et al., 2018). Other than gene recombination, environmental factors such as temperature have been shown to potentially affect the genetic variation of effector pool (Matsuba et al., 2013; L. Yang et al., 2018). Also, since most effectors are implicated in infection and precisely manipulating plant cellular processes for disease development, therefore, effectors are expected to evolve differently due the coevolution between the pathogen and host.

These variations in effector genes has led to the breakdown of main gene-facilitated plant resistances (Cooke et al., 2012). In addition, effector variation within a population means that these genes can be lost without substantial impact on the pathogen's virulence since they can act redundantly by altering the same host signalling pathway (Zheng et al., 2014). This makes the effort to breed for durable resistance in plants a tall order. 
Despite the spectacular diversity of effectors in plant pathogens, a subset of these secreted proteins is reportedly conserved among pathogens and are commonly referred to as core effectors. These are effectors that are widely distributed across the population of a particular pathogen and contribute to the virulence of that pathogen(Cooke et al., 2012; Dangl et al., 2013). Currently, the term 'core effectors' is inclusive of effectors not only conserved within strains of a species, but also across diverse species also known as orthologous genes. As these effectors are critical in virulence, the pathogen incurs a fitness cost in evolving them.

The foundation of core effectors was first laid when high-throughput genome sequencing of 65 strains of Xanthomonas axonopodis pv.manihotis (Xam), a causal agent of cassava bacterial blight, showed a total of nine effectors conserved across all those strains (Bart et al., 2012). This set of core effectors now serves as targets to identify cognate resistance $(R)$ genes in wild species of Manihot and potentially other related plants in the Euphorbiaceae (Bart et al., 2012; Dangl et al., 2013);. Since then, various studies have been carried out to identify and characterize core effectors in other plant pathogens (Table 1). We reason that since core effectors are authenticated virulence players in various plant pathogens, it is probable that the virulence strategy is shared by distinct plant pathogens.

\section{Do oomycetes harbour core RxLR effectors (CREs)?}

Over the last decade, the genomes of over 65 oomycete species have been sequenced (Benson et al., 2012; McGowan \& Fitzpatrick, 2020). Analyses of these genomes revealed that the oomycete genome sizes vary from 32.1 to $295.3 \mathrm{Mb}$ in Peronospora effuse and Plasmopara obducens, respectively (Fletcher et al., 2019; McGowan \& Fitzpatrick, 2020). In addition, the RxLR secretomes of oomycetes vary significantly. For instance, predictions of RxLRs in the genomes of P. multivora, P. infestans, $P$. palmivora and P. megakarya encoded 84, 563, 991 and 1181 RxLRs, respectively (Ali et al., 2017; Haas et al., 2009; Vetukuri et al., 2018). Effector variation even within a 
species is common. This effector content variation has been attributed to horizontal gene acquisition (HGA) in most oomycete pathogens (Savory et al., 2015). Beside HGA, oomycetes have been shown to lose genes that do not have targets in the new host, leading to host jumps (Sharma et al., 2014; Thines, 2019). Also, since most effectors including RxLRs are small, their rapid variation would result in a loss of sequence similarity. Despite the gain and loss of RxLRs in oomycetes due to various selection pressures from plant hosts as well as ecosystems, a small number of them is conserved across the population of a particular species and/or the genus. The availability of sequenced genomes for a variety of genotypes of the same species of oomycetes has been a catalyst in identification of CREs. In addition, the presence of N-terminal signature motifs mainly the RxLR-ERR and signal peptide (Armenteros et al., 2019) has enabled the identification of various CREs using in silico bioinformatics-based approaches. These approaches allow large-scale identification of oomycete RxLR effector arsenals. There is a growing evidence of CREs identified in a large number of oomycetes using computational approaches (Armitage et al., 2018; Dalio et al., 2018; Pecrix et al., 2019; Rojas-Estevez et al., 2020). A typical pipeline used in mining CREs in oomycete species is illustrated in Figure 1 leading to identification of putative CREs in some oomycete species (Figure 2). A general approach of the pipeline begins with mining of the genome for effectors by determining their ability to be secreted (presence of a signal peptide and lack of transmembrane domains) and finally, authentication of these effectors through in planta expression patterns as depicted in Figure 1.

Besides bioinformatics prediction of putative CREs, genome comparisons can be employed to identify these effectors (Mestre et al., 2016). For instance, comparing genomes of strains of a species can aid in the identification of sequence polymorphism particularly single nucleotide polymorphisms (SNPs) in the proteincoding regions of effectors (Anderson et al., 2012; Cooke et al., 2012). Ideally, CREs are well-marked with a high ratio of substitutions that change amino acids (non- 
synonymous) to substitutions that do not change amino acids (synonymous) coupled with significantly low or no copy number variation amongst the genes while the opposite applies to non-conserved RxLRs (Cooke et al., 2012; Win et al., 2007). These distinct variations could be attributed to the fact that conserved effectors are believed to be ancestral and because of their obligate role in pathogen virulence, they are subject to purifying selection (Lindeberg et al., 2012). Genomic comparison of the potato late blight pathogen $P$. infestans recorded about 563 RxLRs with 45 of these being shared among the three strains (06_3924A, NL07434, and T304) and expressed in planta as CREs (Cooke et al., 2012). Among these 45 CREs, 5 Avr genes (Avr2, Avr3a, Avrblb1, Avrblb2 and Avrvnt1) are known gain-of-virulence variants (Vleeshouwers \& Oliver, 2014). It was further revealed that Avr2 and Avr3a contain sequence polymorphisms that potentially enable them to evade recognition by cognate $\mathrm{R}$ genes in plants. Likewise, CREs Avrblb1, Avrblb2 and Avrvnt1 have intact coding sequences that are induced during infection (Cooke et al., 2012). These three Avr effectors are therefore predicted to be recognized by their cognate immunoreceptors. (Yin et al., 2017) employed next-generation transcriptome deep sequencing strategy coupled with sequence polymorphisms to identify 18 candidate CREs in P. infestans. For CRE candidate to be bona fide effectors, the following must be taken into consideration; (1) conserved sequences among various strains in the population, (2) high expression during infection and (3) potential essential functions in pathogenesis (Cooke et al., 2012; Dangl et al., 2013; Yin et al., 2017). A recent study on genome re-sequencing of $P$. sojae identified a set of 471 RxLR effectors across 26 genomes of the pathogen with 42 being conserved as well as expressed in planta. Among the 42 core effectors, two RxLR effectors, PsAvh241 and PsAvh23 had been demonstrated as essential for full virulence of P. sojae (Kong et al., 2017; Yu et al., 2012)This insinuates that the remaining 40 effectors could be critical in the infection process. 
At this point, it is evident that bioinformatics-based approaches have been successfully used in CREs identification. However, in this success, therein lies a trap. With this approach, effector proteins lacking a signal peptide (SP) are discarded. However, these SP-lacking RxLR effector proteins have been shown to be secreted unconventionally (Liu et al., 2014). Specifically, RxLR candidate effectors of $P$. infestans were detected in the pellet samples of the culture filtrate, providing compelling evidence that these effectors could be delivered using the extracellular vesicles (EVs) (S. Wang et al., 2018). Therefore, most CREs could be overlooked when using bioinformatics approaches only. Also, false positives may be reported using these prediction approaches. It is unfortunate that to date, there is still no reliable algorithms to predict unconventionally secreted proteins in filamentous plant pathogens including oomycetes. Mass spectrometry is a powerful technique that can be used to solve this problem. It has been previously employed in validating computationally predicted RxLR effector proteins to be secreted as well as identifying extracellular proteins that lack typical SP, which would then be overlooked (McGowan et al., 2020; Meijer et al., 2014; Severino et al., 2014)

Taken together, coupling in silico-based approaches with experimental techniques such as mass spectrometry could be the gold standard method for identifying CREs and more so, novel CREs that have no matches in public databases. In addition, there is need to verify whether indeed RxLR effectors form part o the cargo that is being delivered to the extracellular of the pathogen using EVs. More importantly, the association of RxLRs with EVs during their biogenesis is worth investigating.

\section{Do Core RxLR effectors play a role in virulence?}

The evolutionary arms race between plant hosts and pathogens has led to plants developing a multi-layered immune response. This immune response is therefore presented in the form of pathogen-associated molecular pattern (PAMP)-triggered 
immunity (PTI) and effector-triggered immunity (ETI) (Saijo \& Loo, 2020). However, CREs subdue host immune responses by targeting key components leading to disease proliferation. In most cases, these targeted components are central cellular processes/proteins that are conserved across diverse plant species. The first report was recorded in 2014 demonstrating that P. sojae RxLR effector PsPSR2 that is conserved among eight Phytophthora spp, suppresses RNA silencing activity, which is conserved in various plants(Xiong et al., 2014). Since then, a few other studies on CREs have been conducted to determine the role of oomycetes CREs in virulence. For instance, P. sojae RxLR effector (PsAvh73) homologous to oomycete Hyaloperonospora arabidopsidis effector (HaRxL23) was reported to suppress PTI response in Nicotiana benthamiana and ETI in Glycine max (Deb et al., 2018).

Phytophthora brassicae effector, RxLR24, was showed to be highly conserved among most successful species of Phytophthora such as P. infestans, P. sojae, and P. parasitica var. nicotianae (Tomczynska et al., 2018). Further, characterization of this effector and its close homolog in P. infestans, Pi RxLR24 revealed that the two effectors localize to the plasma and vesicular membranes, where they associate with members of the RABA GTPase subfamily, hence interfering with vesicle tracking of the host plant (Tomczynska et al., 2018). In a separate study, three core effectors of P. parasitica PpRxLR2, PpRxLR3, and PpRxLR5 were highly expressed in N. benthamiana leaves during infection (Dalio et al., 2018). Further analysis showed that effector PpRxLR2 enhanced the virulence of $P$. parasitica via complete suppression of the INF-1induced PCD while effectors PpRxLR3 and PpRxLR5 suppressed host plant defenses nonetheless, it was to a less significant extent when compared with PpRxLR2. Two CREs, REX3 and REX2 of the broad host-range oomycete P. palmivora were demonstrated to promote disease development upon expression, where effector REX3 enhanced virulence of the pathogen by interfering with host secretion pathways (Evangelisti et al., 2017). The well-studied oomycete P. infestans was reported to harbour a total of 18 CREs that are not only expressed during the early 
phase of infection but also contribute to disease development by inhibiting plant defence responses induced by both PTI and ETI (Yin et al., 2017).

Recently, CREs have been reported to target negative regulators of host immunity called susceptibility factors (SFs). A good example is Avr3a-related RxLR effectors that are distributed across diverse Phytophthora species. These effectors target the family of cinnamyl alcohol dehydrogenase 7 (CAD7) leading to downstream suppression of PTI (Li et al., 2019)

Although CREs are said to be highly conserved, their essentiality is not likely to be retained through the conservation of overall proteins but through specific protein domains. From the few existing studies on CREs of oomycetes, there is no specific domain that has been implicated in effector virulence activity (Li et al., 2019; Tomczynska et al., 2018; Xiong et al., 2014). Interestingly, alignment analyses of these CREs reveal the presence of C-terminal W (Trp) and Y (Tyr) motifs. We therefore hypothesize that these motifs could be crucial in virulence activity of CREs of oomycetes. But again, studies have shown that approximately $44 \%$ of Phytophthora RxLR effectors and 26\% of Hyaloperonospora arabidopsidis possess a highly conserved W and Y motif at the C-terminal (Boutemy et al., 2011; J. He et al., 2019). Structural analyses of WY motif(s) have revealed the presence of more than one $\alpha$-helix bundle formed by each motif (Win et al., 2012). It is hypothesized that the $\alpha$-helical-domain which is the "WY-domain", enhances effector adaptation through mutations, while the hydrophobic core fold provides stability and flexibility therefore, implicated in virulence activities of the effector (Boutemy et al., 2011). Following this hypothesis, studies have reported that this hydrophobic core is crucial in effector-host target protein interaction (Du et al., 2015; King et al., 2014; Qiao et al., 2015), cell-death induction (Combier et al., 2019; Xiang et al., 2017) RNA silencing suppression activity (Zhang et al., 2019) and suppression of PTI and ETI events (Deb et al., 2018; Li et al., 2019) 
Although the WY motifs have been associated with effector virulence activity, $P$. infestans RxLR effector PexRD54, was shown to have a total of five WY repeats but surprisingly, the virulence activity of the effector was dependent on a C-terminal ATG8-interaction motif (AIM) that binds proteins related to autophagy (ATG8) (Dagdas et al., 2016; Maqbool et al., 2016). Further analysis of PexRD54 revealed that the AIM motif, at the C terminus of the effector, is linked to the last WY domain by a short helix (Dagdas et al., 2016). Therefore, we can hypothesize that the main function of WY motifs in RxLRs is to act as a "dais" to introduce functional motifs or domains for interaction with host plant proteins. Recently, the highly conserved Avr3a-like effectors from Phytophthora species showed a conserved function by targeting plant cinnamyl alcohol dehydrogenase 7 (CAD7) subfamily (Li et al., 2019). Amazingly, this function was independent of a putative enzyme active site of these effectors. Since the sequence conservation of these proteins revealed the presence of conserved WY motif at the C-terminal, we can therefore propose that WY motif could be responsible for Avr3a-like effectors-CAD7 interaction.

Although it appears that $\mathrm{W}-\mathrm{Y}$ motifs are crucial in virulence activity of most RxLR effectors in oomycetes, it is not crystal clear whether these motifs are key players in CREs activity. Therefore, dissecting the structure of CREs using experimental and computational approaches is encouraged. This will inform not only the functional motifs or domains but also the host immune proteins or processes that these CREs target.

\section{Do CREs target core host proteins/processes?}

Ideally, the ability of conserved effectors to target conserved plant proteins and processes is a clever ploy since this provides not only flexibility in the increase of a pathogen's host range but also hastens evolutionary shifts to new hosts (Carella et al., 2018). In addition, since these core effectors are maintained in effector repertories over a long evolutionary time (Depotter \& Doehlemann, 2020), they are likely to 
target conserved elements in the plant immune system or metabolism that facilitate host colonization. It is also important to know that these targeted host proteins and processes are "the candy liked by many" since they are crucial processes that cannot be altered or eliminated without a complete damage to plant fitness. This core effector for conserved host protein concept has been witnessed in plant fungal effectors (Hemetsberger et al., 2015; Irieda et al., 2019) and also in effectors (AvrB, AvrPto, HopAI1) of bacteria such as Pseudomonas syringae (Alfano et al., 2000); (Badel et al., 2006; DebRoy et al., 2004) In oomycetes, this concept has not been sufficiently documented. Studies have demonstrated that evolutionarily conserved RxLR effectors in oomycetes Hyaloperonospora arabidopsidis and P. sojae can suppress immunity in plant species that are divergent from the source pathogen's host (Anderson et al., 2012; Deb et al., 2018)). In the same token, several conserved RxLR effectors from oomycete Phytophthora agathidicida, a pathogen of gymnosperms, were revealed to interact with the immune system of model angiosperm plants (Nicotiana $s p p)$, in a similar way to that of angiosperm pathogens (Guo et al., 2020). These findings provide a hint on possible interaction of conserved effectors with conserved host targets. Recently, Avr3a-like conserved effectors from Phytophthora pathogens were reported to target negative regulator of immunity, cinnamyl alcohol dehydrogenase 7 (CAD7) in both Arabidopsis thaliana and Nicotiana benthamiana leading to disease development (Li et al., 2019). The notion of oomycetes' effectors targeting negative regulators/susceptibility factors is currently a fertile ground as reviewed by (Q. He et al., 2020)

At this point, we cannot confidently conclude that CREs of oomycetes target broadly conserved plant proteins, nonetheless, the presence of core effectors in these pathogens could explain the success of most broad host-range oomycetes notably Phytophthora species. In order to fully understand core-core concept, functional characterization of core effectors is key. This can be achieved through screening for protein-protein interaction using yeast two-hybrid system (Y2H) (Boevink et al., 
2016; Mukhtar et al., 2011), followed by validation of the interaction through coimmunoprecipitation (Petre et al., 2015). Other validation methods include Biotinylation (Roux et al., 2013) and bimolecular fluorescence complementation (BiFC) (Graciet \& Wellmer, 2010; Miller et al., 2015). Further, mutation analyses like site-directed mutagenesis (Sang et al., 2020; Whigham et al., 2015)and virus induced gene silencing, VIGs (Ren et al., 2019; L. Yang et al., 2016) can be performed to gain more insight on effector-host protein interaction.

\section{Can core effectors be useful in breeding for durable resistance?}

Currently, there is a paradigm shift from conventional to breeding for durable resistance. Effectoromics is a high-throughput functional genomics approach that employs the use of effectors to probe plant germplasm (Pais et al., 2013; Vleeshouwers et al., 2008). We reason that since core effectors are present in most strains or species of a pathogen as well as playing an important role in virulence, therefore, pathogen cannot easily lose them even after a new resistance gene is deployed in the host. Consequently, $R$ gene products that recognize such effectors are anticipated to be more durable than resistance gene products that perceive non conserved effectors.

The journey to durable resistance using core effectors starts with employing nextgeneration sequencing technologies to sequence and assemble genomes of various pathogens that are responsible for disease in different fields. Using computational approaches, the most successful core effectors in these strains can be identified. Successively, these core effectors can be employed as probes in screening for cognate $R$ proteins from wild germ-plasm using mainly transient co-expression assays (Rietman et al., 2012) followed by either marker-assisted breeding or transgene deployment (Dangl et al., 2013; Vleeshouwers et al., 2011; H. Yang et al., 2012). Validation of these new $R$ genes could be enhanced by new genome-editing methods like clustered regulatory interspaced short palindromic repeat (CRISPR) 
technologies (W. Wang et al., 2018). Screening for potential $R$ proteins that recognise core effectors has been attempted in Ralstonia solanacearum, the causal agent of bacterial wilt on numerous solanaceous species (Clarke et al., 2015). The study reported that eight of core effectors of the pathogen, triggered a response in diverse host plants (eggplant, tomato pepper and lettuce). This led to the conclusion that these genotypes could be harbouring resistance genes that can be identified and mapped, cloned, and expressed in host plant.

Although core effectors appear to be the perfect targets in breeding for durable resistance, some studies have reported that due to long evolution of plant-pathogen interaction, there is a possibility of complex mechanisms coming into place to shield conserved effectors from recognition (Bourras et al., 2015; Kombrink \& Thomma, 2013; Plissonneau et al., 2016). For instance, the virulence activity of the conserved pathogen-secreted xyloglucan specific endoglucanase (PsXEG1) an apoplastic effector of $P$. sojae was shown to be protected by its paralog that is enzymatically inactive by binding more tightly to the host apoplastic glucanase inhibitor GmGIP1 than PsXEG1 (Ma et al., 2017). Whether this is also the case in extracellular effectors like RxLRs needs to be investigated. Another hurdle to utilization of core effectors for durable resistance has been encountered in the well-conserved P. infestans RxLR effector Avr3a (Armstrong et al., 2005; Cárdenas et al., 2011). This effector exists in two alleles $\left(A v r 3 a^{K I}\right.$ and $\left.A v r 3 a^{E M}\right)$, and this translates to a difference of two amino acids in the mature protein where AVR3aKI is recognized by R3a while AVR3aEM evades R3a recognition (Armstrong et al., 2005). Therefore, although Avr3a has been marked as a potential candidate in breeding for durable resistance, the challenge now is to produce potato plants with an enhanced resistance spectrum and durability by integrating naturally occurring $R$ genes or engineered, synthetic $R$ genes with extended pathogen recognition precisions that comprises Avr $3 a^{E M}$ recognition. 
Another potential way of exploiting CREs for durable resistance breeding is capitalizing on their ability to target susceptibility factors (SFs) (Li et al., 2019). This can be attained by identifying susceptibility genes using protein-protein interaction methods such as yeast-two hybrid screening (Boevink et al., 2016; Bos et al., 2010). After the identification, inactivation of SF genes by mutations is done with an aim of interfering with the ability of the effectors to associate with their host partners (Gawehns et al., 2013; van Schie \& Takken, 2014). For instance, potato plants showed complete resistance to $P$. infestans pathogen after successful knockdown of six SF genes (Sun et al., 2016). Although this might seem to be an avenue to breeding for durable resistance using core effectors, there is a cause for alarm since mutations in susceptibility genes have been linked to pleiotropic effects precisely dwarfism and sensitivity to other stresses (Gawehns et al. 2013). This limits the utilization of these genes in agriculture.

\section{The future of CREs Research}

There is a clear potential for core effectors to target conserved processes in diverse host plants (Irieda et al., 2019). However, studies on the ability of CREs in oomycetes to target conserved host processes/protein have not been fully explored. Therefore, functional studies on these effectors are highly encouraged. The emerging reports that oomycetes species harbour CREs shed light on important virulence roles played by these effectors. However, some key questions remain to be answered: Why do oomycetes conserve some RxLRs? Do these effectors play a conserved role in host plants? Do these effectors act as probes in screening for cognate $R$ genes in search for durable resistance in plants? Providing answers to these questions can potentially further advance the field. Further, studies should also combine biochemical analyses with genetics and biophysical studies to address these questions in order to gain a thorough understanding of the biology of core effectors in oomycetes. 
Although less has been documented on core RxLR effectors in oomycetes, the few existing studies have identified putative CREs through in silico prediction-based approaches. The task now is to validate the expression of these effectors in planta. In addition, functional characterization is worth doing to dissect these effectors and hence identifying specific domains that are conserved as well as important in virulence of the effector.

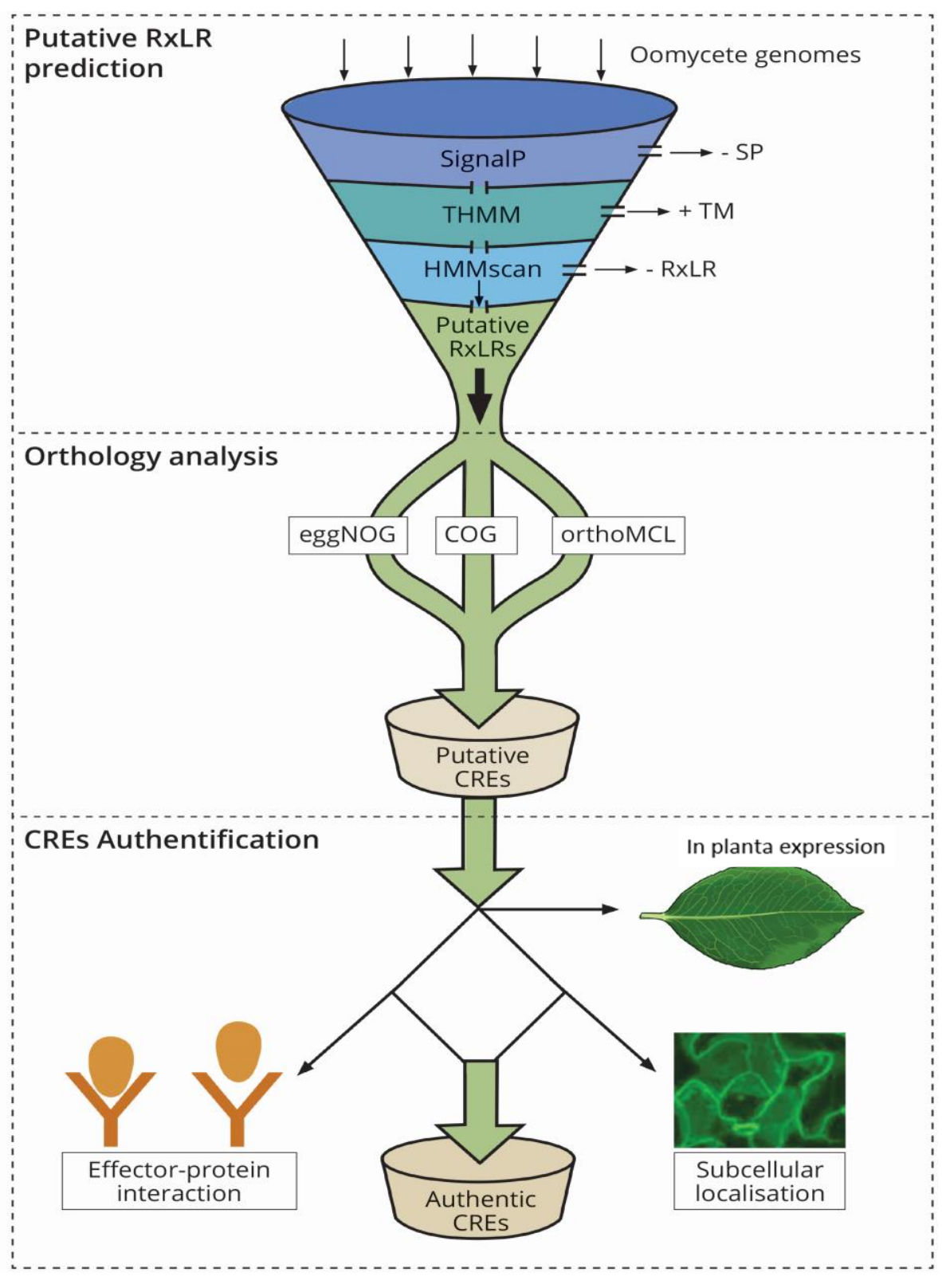

Figure 1: A schematic representation of in silico prediction and validation of putative CREs in oomycetes. The secretome prediction pipeline begins with the removal of 
proteins without a signal peptide (SP) while retaining those with transmembrane domain, by use of signalP tool and THMM, respectively. Effector proteins with a transmembrane domain (TM) are discarded after signal peptide cleavage as these proteins are not likely to be retained in the plasma membrane. This is followed by removing effector proteins without the signature RxLR motif using HMMscan tool. Orthology analysis is done to determine RxLRs that are conserved within strains or within species of a pathogen (CREs) using orthologyanalysis tools like COG, eggNOG or orthofinder tool. The final output is composed of putative secreted CREs with SP, RxLR motif and without the TM. This output is further authenticated through in planta expression to ascertain their role in virulence for instance, their role in enhancing/suppressing host immunity, where they localize in planta using confocal microscopy as well as interacting proteins within host partners. Since these authentic CREs lack the freedom to mutate, the host immunity response to them effectively hence durable resistance.
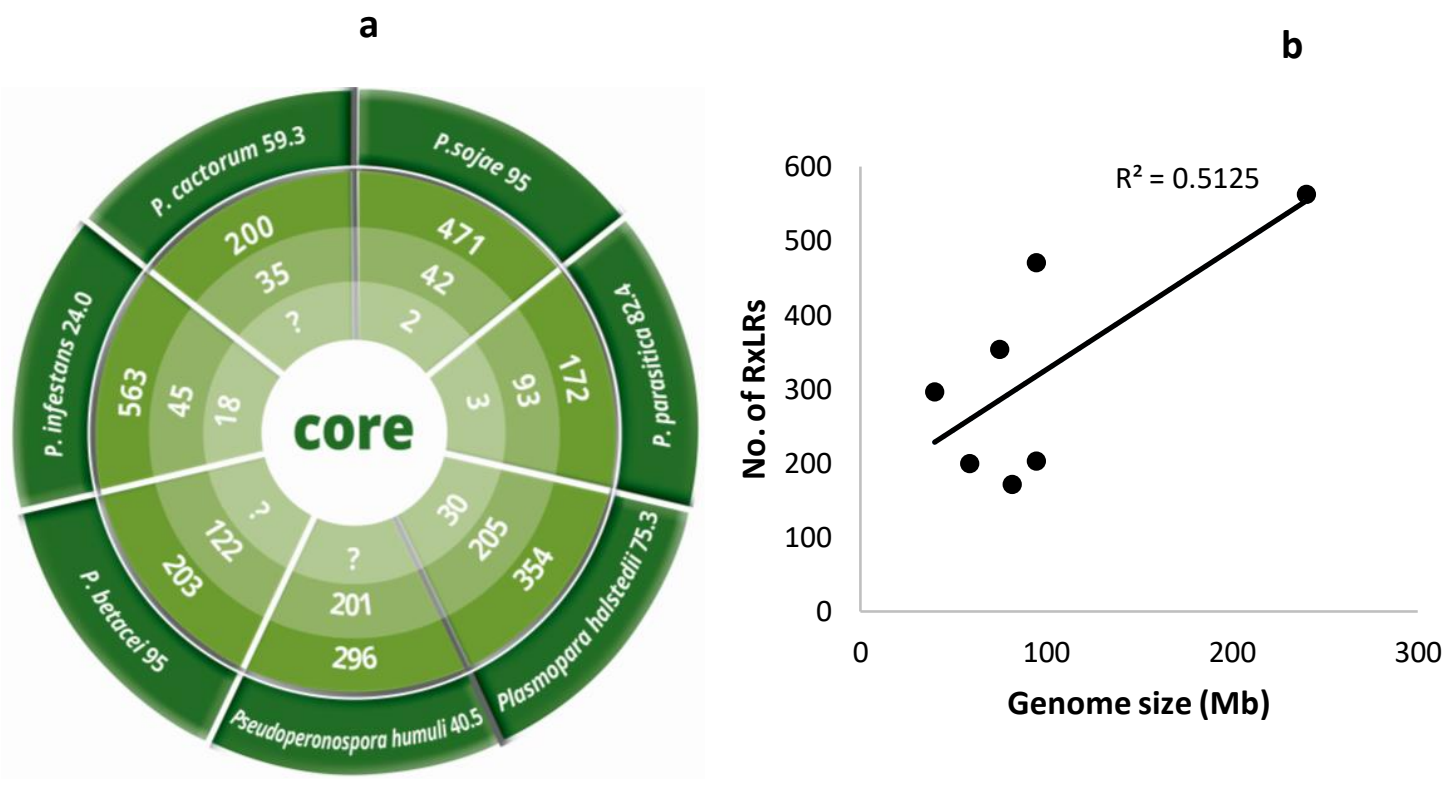

Figure 2: Illustration of phytopathogenic oomycetes with their respective genome sizes $(\mathrm{Mb})$ on the first ring, with most of them being Phytophthora spp (P.). In terms 
of genome size, P. infestans and Pseudoperonospora humulis recorded the highest $(240 \mathrm{Mb})$ and lowest $(40.5 \mathrm{Mb})$ genomes, respectively. The second ring is the total number of predicted RxLRs ranging from 200 in P. cactorum to 563 in P. infestans. The third ring is the total of putative CREs while the fourth ring is the total number of authentic CREs with Plasmopara halstedii recording a total of 30 CREs. Insignificant correlation between genome size and the number of predicted RxLRs in oomycetes was recorded (b).

Table 1: Core effectors in different groups of plant pathogens 


\begin{tabular}{|c|c|c|c|c|}
\hline Group & Organism & $\begin{array}{l}\text { Identified } \\
\text { core effectors }\end{array}$ & Virulence role & Reference \\
\hline \multirow[t]{2}{*}{ Oomycete } & Plasmopara halstedii & $354(30)$ & $\begin{array}{l}\text { Suppress pattern- } \\
\text { triggered immunity and } \\
\text { some induce } \\
\text { hypersensitive } \\
\text { responses }\end{array}$ & Pecrix et al., 2018 \\
\hline & $\begin{array}{l}\text { Hyaloperonospora } \\
\text { arabidopsidis }\end{array}$ & $18(4)$ & $\begin{array}{l}\text { RXLR29 was shown to } \\
\text { suppress pathogen- } \\
\text { induced } \\
\text { deposition }\end{array}$ & Cabral et al., 2011 \\
\hline \multirow[t]{2}{*}{ Bacteria } & $\begin{array}{l}\text { Ralstonia } \\
\text { solanacearum }\end{array}$ & $60-75(32)$ & - & $\begin{array}{l}\text { Peeters et al., 2013; } \\
\text { Deslandes and } \\
\text { Genin, 2014; Clarke } \\
\text { et al., } 2015\end{array}$ \\
\hline & $\begin{array}{l}\text { Xanthomonas } \\
\text { arboricola }\end{array}$ & $57(11)$ & - & Merda et al., 2017 \\
\hline \multirow[t]{3}{*}{ Fungi } & Ustilago. virens & $193(18)$ & $\begin{array}{l}\text { UV_1261 suppress host } \\
\text { plant hypersensitive } \\
\text { responses }\end{array}$ & $\begin{array}{l}\text { (Zhang et al. 2014; } \\
\text { Fang et al. 2016; Fan } \\
\text { et al., } 2019\end{array}$ \\
\hline & Zymoseptoria tritici & $591(153)$ & - & $\begin{array}{l}\text { Plissonneau et al., } \\
2018\end{array}$ \\
\hline & U. maydis & $467(202)$ & $\begin{array}{l}\text { Pep1 inhibits the } \\
\text { activity of the apoplastic } \\
\text { maize peroxidase }\end{array}$ & $\begin{array}{l}\text { Hemetsberger et } \\
\text { al.,2012). } \\
\text { THemetsberger et }\end{array}$ \\
\hline
\end{tabular}




\begin{tabular}{|c|c|c|}
\hline & $\begin{array}{l}\text { POX12 } \\
\text { Cce1 hypothesized to } \\
\text { inhibit early plant } \\
\text { defense responses in the } \\
\text { apoplast } \\
\text { Rsp3 has a conserved } \\
\text { virulence role of } \\
\text { protecting the fungal } \\
\text { hyphae from maize } \\
\text { antifungal proteins } \\
\text { activity. } \\
\text { Sta1 a novel core } \\
\text { effector with virulence } \\
\text { role through host cell- } \\
\text { wall modification for } \\
\text { disease progression }\end{array}$ & $\begin{array}{l}\text { al., 2015; Lanver et } \\
\text { al., 2017;Schuster et } \\
\text { al., 2018;Seitner et } \\
\text { al., } 2018 \\
\text { Ma et al., } 2018 \\
\text { Tanaka et al., } 2020\end{array}$ \\
\hline $\begin{array}{l}\text { Colletotrichum } \\
\text { orbiculare }\end{array}$ & $\begin{array}{lr}\text { necrosis-inducing } \\
\text { secreted } & \text { protein } 1 \\
\text { (NIS1), } & \text { targets } \\
\text { conserved } & \text { immune } \\
\text { kinases } & \text { hence } \\
\text { interfering } & \text { with } \quad \text { PTI } \\
\text { signalling } & \end{array}$ & Irieda et al., 2019 \\
\hline
\end{tabular}

Figures in and outside the parenthesis are the core and potentially secreted effectors respectively 


\section{References}

Adhikari, B. N., Hamilton, J. P., Zerillo, M. M., Tisserat, N., Lévesque, C. A., \& Buell, C. R. (2013). Comparative genomics reveals insight into virulence strategies of plant pathogenic oomycetes. PloS one, 8(10), e75072.

Ai, G., Yang, K., Ye, W., Tian, Y., Du, Y., Zhu, H., . . Peng, H. (2020). Prediction and Characterization of RXLR Effectors in Pythium Species. Molecular Plant-Microbe Interactions(ja).

Alfano, J. R., Charkowski, A. O., Deng, W.-L., Badel, J. L., Petnicki-Ocwieja, T., Van Dijk, K., \& Collmer, A. (2000). The Pseudomonas syringae Hrp pathogenicity island has a tripartite mosaic structure composed of a cluster of type III secretion genes bounded by exchangeable effector and conserved effector loci that contribute to parasitic fitness and pathogenicity in plants. Proceedings of the National Academy of Sciences, 97(9), 4856-4861.

Ali, S. S., Shao, J., Lary, D. J., Kronmiller, B. A., Shen, D., Strem, M. D., . . Ten Hoopen, G. M. (2017). Phytophthora megakarya and Phytophthora palmivora, closely related causal agents of cacao black pod rot, underwent increases in genome sizes and gene numbers by different mechanisms. Genome biology and evolution, 9(3), 536-557.

Anderson, R. G., Casady, M. S., Fee, R. A., Vaughan, M. M., Deb, D., Fedkenheuer, K., . . . McDowell, J. M. (2012). Homologous RXLR effectors from Hyaloperonospora arabidopsidis and Phytophthora sojae suppress immunity in distantly related plants. The Plant Journal, 72(6), 882-893.

Anderson, R. G., Deb, D., Fedkenheuer, K., \& McDowell, J. M. (2015). Recent progress in RXLR effector research. Molecular Plant-Microbe Interactions, 28(10), 1063-1072.

Armenteros, J. J. A., Tsirigos, K. D., Sønderby, C. K., Petersen, T. N., Winther, O., Brunak, S., .. . Nielsen, H. (2019). SignalP 5.0 improves signal peptide predictions using deep neural networks. Nature biotechnology, 37(4), 420-423.

Armitage, A. D., Lysøe, E., Nellist, C. F., Lewis, L. A., Cano, L. M., Harrison, R. J., \& Brurberg, M. B. (2018). Bioinformatic characterisation of the effector repertoire of the strawberry pathogen Phytophthora cactorum. PloS one, 13(10), e0202305.

Armstrong, M. R., Whisson, S. C., Pritchard, L., Bos, J. I., Venter, E., Avrova, A. O., . . Cherevach, I. (2005). An ancestral oomycete locus contains late blight avirulence gene Avr3a, encoding a protein that is recognized in the host cytoplasm. Proceedings of the National Academy of Sciences, 102(21), 7766-7771.

Badel, J. L., Shimizu, R., Oh, H.-S., \& Collmer, A. (2006). A Pseudomonas syringae pv. tomato avrE1/hopM1 mutant is severely reduced in growth and lesion formation in tomato. Molecular Plant-Microbe Interactions, 19(2), 99-111.

Baltrus, D. A., Nishimura, M. T., Romanchuk, A., Chang, J. H., Mukhtar, M. S., Cherkis, K., . . Dangl, J. L. (2011). Dynamic evolution of pathogenicity revealed by sequencing and comparative genomics of 19 Pseudomonas syringae isolates. PLoS Pathog, 7(7), e1002132.

Bart, R., Cohn, M., Kassen, A., McCallum, E. J., Shybut, M., Petriello, A., . . Alicai, T. (2012). Highthroughput genomic sequencing of cassava bacterial blight strains identifies conserved effectors to target for durable resistance. Proceedings of the National Academy of Sciences, 109(28), E1972-E1979.

Benson, D. A., Cavanaugh, M., Clark, K., Karsch-Mizrachi, I., Lipman, D. J., Ostell, J., \& Sayers, E. W. (2012). GenBank. Nucleic acids research, 41(D1), D36-D42.

Birch, P. R., Armstrong, M., Bos, J., Boevink, P., Gilroy, E. M., Taylor, R. M., . . Ewan, R. (2009). Towards understanding the virulence functions of RXLR effectors of the oomycete plant pathogen Phytophthora infestans. Journal of Experimental Botany, 60(4), 1133-1140. 
Boevink, P. C., Birch, P. R., Turnbull, D., \& Whisson, S. C. (2020). Devastating intimacy: the cell biology of plant-Phytophthora interactions. New Phytologist.

Boevink, P. C., Wang, X., McLellan, H., He, Q., Naqvi, S., Armstrong, M. R., . . Tian, Z. (2016). A Phytophthora infestans RXLR effector targets plant PP1c isoforms that promote late blight disease. Nature communications, 7(1), 1-14.

Bos, J. I., Armstrong, M. R., Gilroy, E. M., Boevink, P. C., Hein, I., Taylor, R. M., . . Harrower, B. (2010). Phytophthora infestans effector AVR3a is essential for virulence and manipulates plant immunity by stabilizing host E3 ligase CMPG1. Proceedings of the National Academy of Sciences, 107(21), 9909-9914.

Bourras, S., McNally, K. E., Ben-David, R., Parlange, F., Roffler, S., Praz, C. R., . . Frenkel, Z. (2015). Multiple avirulence loci and allele-specific effector recognition control the Pm3 race-specific resistance of wheat to powdery mildew. The Plant Cell, 27(10), 2991-3012.

Boutemy, L. S., King, S. R., Win, J., Hughes, R. K., Clarke, T. A., Blumenschein, T. M., . . Banfield, M. J. (2011). Structures of Phytophthora RXLR effector proteins a conserved but adaptable fold underpins functional diversity. Journal of Biological Chemistry, 286(41), 35834-35842.

Cárdenas, M., Grajales, A., Sierra, R., Rojas, A., González-Almario, A., Vargas, A., . . Grünwald, N. J. (2011). Genetic diversity of Phytophthora infestans in the Northern Andean region. BMC genetics, 12(1), 23.

Carella, P., Evangelisti, E., \& Schornack, S. (2018). Sticking to it: phytopathogen effector molecules may converge on evolutionarily conserved host targets in green plants. Current opinion in plant biology, 44, 175.

Chepsergon, J., Motaung, T. E., Bellieny-Rabelo, D., \& Moleleki, L. N. (2020). Organize, Don't Agonize: Strategic Success of Phytophthora Species. Microorganisms, 8(6), 917.

Clarke, C. R., Studholme, D. J., Hayes, B., Runde, B., Weisberg, A., Cai, R., . . Castillo, J. A. (2015). Genome-enabled phylogeographic investigation of the quarantine pathogen Ralstonia solanacearum race 3 biovar 2 and screening for sources of resistance against its core effectors. Phytopathology, 105(5), 597-607.

Combier, M., Evangelisti, E., Piron, M.-C., Rengel, D., Legrand, L., Shenhav, L., . . Mestre, P. (2019). A secreted WY-domain-containing protein present in European isolates of the oomycete Plasmopara viticola induces cell death in grapevine and tobacco species. PloS one, 14(7), e0220184.

Cooke, D. E., Cano, L. M., Raffaele, S., Bain, R. A., Cooke, L. R., Etherington, G. J., . . Goss, E. M. (2012). Genome analyses of an aggressive and invasive lineage of the Irish potato famine pathogen. PLoS Pathog, 8(10), e1002940.

Dagdas, Y. F., Belhaj, K., Maqbool, A., Chaparro-Garcia, A., Pandey, P., Petre, B., .. . Sklenar, J. (2016). An effector of the Irish potato famine pathogen antagonizes a host autophagy cargo receptor. Elife, 5, e10856.

Dalio, R., Maximo, H., Oliveira, T., Dias, R., Breton, M., Felizatti, H., \& Machado, M. (2018). Phytophthora parasitica effector PpRxLR2 suppresses Nicotiana benthamiana immunity. Molecular Plant-Microbe Interactions, 31(4), 481-493.

Dangl, J. L., Horvath, D. M., \& Staskawicz, B. J. (2013). Pivoting the plant immune system from dissection to deployment. Science, 341(6147), 746-751.

De Jonge, R., Van Esse, H. P., Kombrink, A., Shinya, T., Desaki, Y., Bours, R., ... Thomma, B. P. (2010). Conserved fungal LysM effector Ecp6 prevents chitin-triggered immunity in plants. Science, 329(5994), 953-955.

Deb, D., Anderson, R. G., How-Yew-Kin, T., Tyler, B. M., \& McDowell, J. M. (2018). Conserved RxLR effectors from oomycetes Hyaloperonospora arabidopsidis and Phytophthora sojae suppress PAMP-and effector-triggered immunity in diverse plants. Molecular Plant-Microbe Interactions, 31(3), 374-385. 
DebRoy, S., Thilmony, R., Kwack, Y.-B., Nomura, K., \& He, S. Y. (2004). A family of conserved bacterial effectors inhibits salicylic acid-mediated basal immunity and promotes disease necrosis in plants. Proceedings of the National Academy of Sciences, 101(26), 9927-9932.

Depotter, J. R., \& Doehlemann, G. (2020). Target the core: durable plant resistance against filamentous plant pathogens through effector recognition. Pest Management Science, 76(2), 426-431.

Du, Y., Mpina, M. H., Birch, P. R., Bouwmeester, K., \& Govers, F. (2015). Phytophthora infestans RXLR effector AVR1 interacts with exocyst component Sec5 to manipulate plant immunity. Plant physiology, 169(3), 1975-1990.

Dussert, Y., Mazet, I. D., Couture, C., Gouzy, J., Piron, M.-C., Kuchly, C., . . Delmotte, F. (2019). A high-quality grapevine downy mildew genome assembly reveals rapidly evolving and lineage-specific putative host adaptation genes. Genome biology and evolution, 11(3), 954-969.

Evangelisti, E., Gogleva, A., Hainaux, T., Doumane, M., Tulin, F., Quan, C., . . Schornack, S. (2017). Time-resolved dual transcriptomics reveal early induced Nicotiana benthamiana root genes and conserved infection-promoting Phytophthora palmivora effectors. BMC biology, 15(1), 39.

Fletcher, K., Gil, J., Bertier, L. D., Kenefick, A., Wood, K. J., Zhang, L., .. Wong, J. (2019). Genomic signatures of heterokaryosis in the oomycete pathogen Bremia lactucae. Nature communications, 10(1), 1-13.

Gawehns, F., Cornelissen, B. J., \& Takken, F. L. (2013). The potential of effector-target genes in breeding for plant innate immunity. Microbial biotechnology, 6(3), 223-229.

Graciet, E., \& Wellmer, F. (2010). The plant N-end rule pathway: structure and functions. Trends in plant science, 15(8), 447-453.

Guo, Y., Dupont, P. Y., Mesarich, C. H., Yang, B., McDougal, R. L., Panda, P., ... Win, J. (2020). Functional analysis of RXLR effectors from the New Zealand kauri dieback pathogen Phytophthora agathidicida. Molecular plant pathology, 21(9), 1131-1148.

Haas, B. J., Kamoun, S., Zody, M. C., Jiang, R. H., Handsaker, R. E., Cano, L. M., . . Torto-Alalibo, T. (2009). Genome sequence and analysis of the Irish potato famine pathogen Phytophthora infestans. Nature, 461(7262), 393-398.

Hardham, A. R. (2005). Phytophthora cinnamomi. Molecular plant pathology, 6(6), 589-604.

He, J., Ye, W., Choi, D. S., Wu, B., Zhai, Y., Guo, B., ... Ma, W. (2019). Structural analysis of Phytophthora suppressor of RNA silencing 2 (PSR2) reveals a conserved modular fold contributing to virulence. Proceedings of the National Academy of Sciences, 116(16), 8054-8059.

He, Q., McLellan, H., Boevink, P. C., \& Birch, P. R. (2020). All roads lead to susceptibility: the many modes-of-action of fungal and oomycete intracellular effectors. Plant Communications, 100050.

Hemetsberger, C., Mueller, A. N., Matei, A., Herrberger, C., Hensel, G., Kumlehn, J., . . . Hückelhoven, R. (2015). The fungal core effector P ep1 is conserved across smuts of dicots and monocots. New Phytologist, 206(3), 1116-1126.

Irieda, H., Inoue, Y., Mori, M., Yamada, K., Oshikawa, Y., Saitoh, H., . . Kosaka, A. (2019). Conserved fungal effector suppresses PAMP-triggered immunity by targeting plant immune kinases. Proceedings of the National Academy of Sciences, 116(2), 496-505.

Jiang, R. H., Tripathy, S., Govers, F., \& Tyler, B. M. (2008). RXLR effector reservoir in two Phytophthora species is dominated by a single rapidly evolving superfamily with more than 700 members. Proceedings of the National Academy of Sciences, 105(12), 4874-4879.

King, S. R., McLellan, H., Boevink, P. C., Armstrong, M. R., Bukharova, T., Sukarta, O., . . Banfield, M. J. (2014). Phytophthora infestans RXLR effector PexRD2 interacts with host MAPKKK $\varepsilon$ to suppress plant immune signaling. The Plant Cell, 26(3), 1345-1359.

Kombrink, A., \& Thomma, B. P. (2013). LysM effectors: secreted proteins supporting fungal life. PLoS Pathog, 9(12), e1003769. 
Kong, L., Qiu, X., Kang, J., Wang, Y., Chen, H., Huang, J., . . Ma, Z. (2017). A Phytophthora effector manipulates host histone acetylation and reprograms defense gene expression to promote infection. Current Biology, 27(7), 981-991.

Krishnan, A., Joseph, L., \& Roy, C. B. (2019). An insight into Hevea-Phytophthora interaction: The story of Hevea defense and Phytophthora counter defense mediated through molecular signalling. Current Plant Biology, 17, 33-41.

Lévesque, C. A., Brouwer, H., Cano, L., Hamilton, J. P., Holt, C., Huitema, E., . . Win, J. (2010). Genome sequence of the necrotrophic plant pathogen Pythium ultimum reveals original pathogenicity mechanisms and effector repertoire. Genome biology, 11(7), R73.

Li, T., Wang, Q., Feng, R., Li, L., Ding, L., Fan, G., . . Huang, G. (2019). Negative regulators of plant immunity derived from cinnamyl alcohol dehydrogenases are targeted by multiple Phytophthora Avr3a-like effectors. New Phytologist.

Lindeberg, M., Cunnac, S., \& Collmer, A. (2012). Pseudomonas syringae type III effector repertoires: last words in endless arguments. Trends in microbiology, 20(4), 199-208.

Liu, T., Song, T., Zhang, X., Yuan, H., Su, L., Li, W., .. Chen, T. (2014). Unconventionally secreted effectors of two filamentous pathogens target plant salicylate biosynthesis. Nature communications, 5(1), 1-10.

Ma, Z., Zhu, L., Song, T., Wang, Y., Zhang, Q., Xia, Y., .. Kong, L. (2017). A paralogous decoy protects Phytophthora sojae apoplastic effector PsXEG1 from a host inhibitor. Science, 355(6326), 710-714.

Maqbool, A., Hughes, R. K., Dagdas, Y. F., Tregidgo, N., Zess, E., Belhaj, K., . . Banfield, M. J. (2016). Structural basis of host autophagy-related protein 8 (ATG8) binding by the Irish potato famine pathogen effector protein PexRD54. Journal of Biological Chemistry, 291(38), 20270-20282.

Marshall, R., Kombrink, A., Motteram, J., Loza-Reyes, E., Lucas, J., Hammond-Kosack, K. E., . . . Rudd, J. J. (2011). Analysis of two in planta expressed LysM effector homologs from the fungus Mycosphaerella graminicola reveals novel functional properties and varying contributions to virulence on wheat. Plant physiology, 156(2), 756-769.

Matsuba, C., Ostrow, D. G., Salomon, M. P., Tolani, A., \& Baer, C. F. (2013). Temperature, stress and spontaneous mutation in Caenorhabditis briggsae and Caenorhabditis elegans. Biology letters, 9(1), 20120334.

McGowan, J., \& Fitzpatrick, D. A. (2020). Recent advances in oomycete genomics. Advances in genetics, 105, 175-228.

McGowan, J., O'Hanlon, R., Owens, R. A., \& Fitzpatrick, D. A. (2020). Comparative Genomic and Proteomic Analyses of Three Widespread Phytophthora Species: Phytophthora chlamydospora, Phytophthora gonapodyides and Phytophthora pseudosyringae. Microorganisms, 8(5), 653.

Meijer, H. J., Mancuso, F. M., Espadas, G., Seidl, M. F., Chiva, C., Govers, F., \& Sabido, E. (2014). Profiling the secretome and extracellular proteome of the potato late blight pathogen Phytophthora infestans. Molecular \& Cellular Proteomics, 13(8), 2101-2113.

Mentlak, T. A., Kombrink, A., Shinya, T., Ryder, L. S., Otomo, I., Saitoh, H., .. Thomma, B. P. (2012). Effector-mediated suppression of chitin-triggered immunity by Magnaporthe oryzae is necessary for rice blast disease. The Plant Cell, 24(1), 322-335.

Mestre, P., Carrere, S., Gouzy, J., Piron, M. C., Tourvieille de Labrouhe, D., Vincourt, P., . . . Godiard, L. (2016). Comparative analysis of expressed CRN and RXLR effectors from two Plasmopara species causing grapevine and sunflower downy mildew. Plant Pathology, 65(5), 767-781.

Miller, K. E., Kim, Y., Huh, W.-K., \& Park, H.-O. (2015). Bimolecular fluorescence complementation (BiFC) analysis: advances and recent applications for genome-wide interaction studies. Journal of molecular biology, 427(11), 2039-2055. 
Mukhtar, M. S., Carvunis, A.-R., Dreze, M., Epple, P., Steinbrenner, J., Moore, J., . . N Nishimura, M. T. (2011). Independently evolved virulence effectors converge onto hubs in a plant immune system network. Science, 333(6042), 596-601.

Pais, M., Win, J., Yoshida, K., Etherington, G. J., Cano, L. M., Raffaele, S., . . Saunders, D. G. (2013). From pathogen genomes to host plant processes: the power of plant parasitic oomycetes. Genome biology, 14(6), 1-10.

Pecrix, Y., Buendia, L., Penouilh-Suzette, C., Marechaux, M., Legrand, L., Bouchez, O., ... Vear, F. (2019). Sunflower resistance to multiple downy mildew pathotypes revealed by recognition of conserved effectors of the oomycete Plasmopara halstedii. The Plant Journal, 97(4), 730748.

Petre, B., Saunders, D. G., Sklenar, J., Lorrain, C., Win, J., Duplessis, S., \& Kamoun, S. (2015). Candidate effector proteins of the rust pathogen Melampsora larici-populina target diverse plant cell compartments. Molecular Plant-Microbe Interactions, 28(6), 689-700.

Plissonneau, C., Daverdin, G., Ollivier, B., Blaise, F., Degrave, A., Fudal, I., . . Balesdent, M. H. (2016). A game of hide and seek between avirulence genes AvrLm4-7 and AvrLm3 in Leptosphaeria maculans. New Phytologist, 209(4), 1613-1624.

Qiao, Y., Shi, J., Zhai, Y., Hou, Y., \& Ma, W. (2015). Phytophthora effector targets a novel component of small RNA pathway in plants to promote infection. Proceedings of the National Academy of Sciences, 112(18), 5850-5855.

Raffaele, S., Farrer, R. A., Cano, L. M., Studholme, D. J., MacLean, D., Thines, M., ... Donofrio, N. M. (2010). Genome evolution following host jumps in the Irish potato famine pathogen lineage. Science, 330(6010), 1540-1543.

Raffaele, S., \& Kamoun, S. (2012). Genome evolution in filamentous plant pathogens: why bigger can be better. Nature Reviews Microbiology, 10(6), 417-430.

Ren, Y., Armstrong, M., Qi, Y., McLellan, H., Zhong, C., Du, B., . . Tian, Z. (2019). Phytophthora infestans RXLR effectors target parallel steps in an immune signal transduction pathway. Plant physiology, 180(4), 2227-2239.

Rietman, H., Bijsterbosch, G., Cano, L. M., Lee, H.-R., Vossen, J. H., Jacobsen, E., . . Vleeshouwers, V. G. (2012). Qualitative and quantitative late blight resistance in the potato cultivar Sarpo Mira is determined by the perception of five distinct RXLR effectors. Molecular PlantMicrobe Interactions, 25(7), 910-919.

Rizzo, D. M., Garbelotto, M., \& Hansen, E. M. (2005). Phytophthora ramorum: integrative research and management of an emerging pathogen in California and Oregon forests. Annu. Rev. Phytopathol., 43, 309-335.

Rojas-Estevez, P., Urbina-Gómez, D. A., Ayala-Usma, D. A., Guayazan-Palacios, N., Mideros, M. F., Bernal, A. J., . . Restrepo, S. (2020). Effector Repertoire of Phytophthora betacei: In Search of Possible Virulence Factors Responsible for Its Host Specificity. Frontiers in Genetics, 11, 579.

Roux, K. J., Kim, D. I., \& Burke, B. (2013). BioID: a screen for protein-protein interactions. Current protocols in protein science, 74(1), 19.23. 11-19.23. 14.

Rujirawat, T., Patumcharoenpol, P., Lohnoo, T., Yingyong, W., Kumsang, Y., Payattikul, P., . . . Garg, G. (2018). Probing the phylogenomics and putative pathogenicity genes of Pythium insidiosum by oomycete genome analyses. Scientific reports, 8(1), 1-14.

Saijo, Y., \& Loo, E. P. i. (2020). Plant immunity in signal integration between biotic and abiotic stress responses. New Phytologist, 225(1), 87-104.

Saitoh, H., Fujisawa, S., Mitsuoka, C., Ito, A., Hirabuchi, A., Ikeda, K., . . Matsumura, H. (2012). Large-scale gene disruption in Magnaporthe oryzae identifies MC69, a secreted protein required for infection by monocot and dicot fungal pathogens. PLoS Pathog, 8(5), e1002711.

Sang, Q., Pajoro, A., Sun, H., Song, B., Yang, X., Stolze, S. C., . . Coupland, G. (2020). Mutagenesis of a Quintuple Mutant Impaired in Environmental Responses Reveals Roles for 
CHROMATIN REMODELING4 in the Arabidopsis Floral Transition. The Plant Cell, 32(5), 1479-1500.

Savory, F., Leonard, G., \& Richards, T. A. (2015). The role of horizontal gene transfer in the evolution of the oomycetes. PLoS Pathog, 11(5), e1004805.

Schornack, S., van Damme, M., Bozkurt, T. O., Cano, L. M., Smoker, M., Thines, M., . . Huitema, E. (2010). Ancient class of translocated oomycete effectors targets the host nucleus. Proceedings of the National Academy of Sciences, 107(40), 17421-17426.

Severino, V., Farina, A., Fleischmann, F., Dalio, R. J., Di Maro, A., Scognamiglio, M., . . . Chambery, A. (2014). Molecular profiling of the Phytophthora plurivora secretome: a step towards understanding the cross-talk between plant pathogenic oomycetes and their hosts. PloS one, 9(11), e112317.

Sharma, R., Mishra, B., Runge, F., \& Thines, M. (2014). Gene loss rather than gene gain is associated with a host jump from monocots to dicots in the smut fungus Melanopsichium pennsylvanicum. Genome biology and evolution, 6(8), 2034-2049.

Sun, K., Wolters, A.-M. A., Vossen, J. H., Rouwet, M. E., Loonen, A. E., Jacobsen, E., . . Bai, Y. (2016). Silencing of six susceptibility genes results in potato late blight resistance. Transgenic research, 25(5), 731-742.

Thines, M. (2019). An evolutionary framework for host shifts-jumping ships for survival. New Phytologist, 224(2), 605-617.

Thines, M., \& Kamoun, S. (2010). Oomycete-plant coevolution: recent advances and future prospects. Current opinion in plant biology, 13(4), 427-433.

Tomczynska, I., Stumpe, M., \& Mauch, F. (2018). A conserved Rx LR effector interacts with host RABA-type GTP ases to inhibit vesicle-mediated secretion of antimicrobial proteins. The Plant Journal, 95(2), 187-203.

Tyler, B. M. (2007). Phytophthora sojae: root rot pathogen of soybean and model oomycete. Molecular plant pathology, 8(1), 1-8.

van Schie, C. C., \& Takken, F. L. (2014). Susceptibility genes 101: how to be a good host. Annual review of phytopathology, 52, 551-581.

Vetukuri, R. R., Tripathy, S., Malar C, M., Panda, A., Kushwaha, S. K., Chawade, A., ... Whisson, S. C. (2018). Draft genome sequence for the tree pathogen Phytophthora plurivora. Genome biology and evolution, 10(9), 2432-2442.

Vleeshouwers, V. G., Finkers, R., Budding, D., Visser, M., Jacobs, M. M., van Berloo, R., . . Krenek, P. (2011). SolRgene: an online database to explore disease resistance genes in tuber-bearing Solanumspecies. BMC plant biology, 11(1), 116.

Vleeshouwers, V. G., \& Oliver, R. P. (2014). Effectors as tools in disease resistance breeding against biotrophic, hemibiotrophic, and necrotrophic plant pathogens. Molecular Plant-Microbe Interactions, 27(3), 196-206.

Vleeshouwers, V. G., Rietman, H., Krenek, P., Champouret, N., Young, C., Oh, S.-K., . . Visser, R. G. (2008). Effector genomics accelerates discovery and functional profiling of potato disease resistance and Phytophthora infestans avirulence genes. PloS one, 3(8), e2875.

Wang, J., Gao, C., Li, L., Cao, W., Dong, R., Ding, X., ... Chu, Z. (2019). Transgenic RXLR effector PITG_15718. 2 suppresses immunity and reduces vegetative growth in potato. International journal of molecular sciences, 20(12), 3031.

Wang, Q., Han, C., Ferreira, A. O., Yu, X., Ye, W., Tripathy, S., . . Sui, Y. (2011). Transcriptional programming and functional interactions within the Phytophthora sojae RXLR effector repertoire. The Plant Cell, 23(6), 2064-2086.

Wang, S., Welsh, L., Thorpe, P., Whisson, S. C., Boevink, P. C., \& Birch, P. R. (2018). The Phytophthora infestans haustorium is a site for secretion of diverse classes of infectionassociated proteins. MBio, 9(4). 
Wang, W., Pan, Q., He, F., Akhunova, A., Chao, S., Trick, H., \& Akhunov, E. (2018).

Transgenerational CRISPR-Cas9 activity facilitates multiplex gene editing in allopolyploid wheat. The CRISPR journal, 1(1), 65-74.

Whigham, E., Qi, S., Mistry, D., Surana, P., Xu, R., Fuerst, G., . . Dickerson, J. A. (2015). Broadly Conserved Fungal Effector BEC1019 Suppresses Host Cell Death and Enhances Pathogen Virulence in Powdery Mildew of Barley (Hordeum vulgare L.)(Retracted). Molecular PlantMicrobe Interactions, 28(9), 968-983.

Whisson, S. C., Boevink, P. C., Wang, S., \& Birch, P. R. (2016). The cell biology of late blight disease. Current Opinion in Microbiology, 34, 127-135.

Win, J., Krasileva, K. V., Kamoun, S., Shirasu, K., Staskawicz, B. J., \& Banfield, M. J. (2012). Sequence divergent RXLR effectors share a structural fold conserved across plant pathogenic oomycete species. PLoS Pathog, 8(1), e1002400.

Win, J., Morgan, W., Bos, J., Krasileva, K. V., Cano, L. M., Chaparro-Garcia, A., ... Kamoun, S. (2007). Adaptive evolution has targeted the C-terminal domain of the RXLR effectors of plant pathogenic oomycetes. The Plant Cell, 19(8), 2349-2369.

Xiang, J., Li, X., Yin, L., Liu, Y., Zhang, Y., Qu, J., \& Lu, J. (2017). A candidate RxLR effector from Plasmopara viticola can elicit immune responses in Nicotiana benthamiana. BMC plant biology, 17(1), 75 .

Xiong, Q., Ye, W., Choi, D., Wong, J., Qiao, Y., Tao, K., . . Ma, W. (2014). Phytophthora suppressor of RNA silencing 2 is a conserved RxLR effector that promotes infection in soybean and Arabidopsis thaliana. Molecular Plant-Microbe Interactions, 27(12), 1379-1389.

Yang, H., Tao, Y., Zheng, Z., Li, C., Sweetingham, M. W., \& Howieson, J. G. (2012). Application of next-generation sequencing for rapid marker development in molecular plant breeding: a case study on anthracnose disease resistance in Lupinus angustifolius L. BMC genomics, 13(1), 318.

Yang, L., McLellan, H., Naqvi, S., He, Q., Boevink, P. C., Armstrong, M., .. Z Zhan, J. (2016). Potato NPH3/RPT2-like protein StNRL1, targeted by a Phytophthora infestans RXLR effector, is a susceptibility factor. Plant physiology, 171(1), 645-657.

Yang, L., Ouyang, H. B., Fang, Z. G., Zhu, W., Wu, E. J., Luo, G. H., ... Zhan, J. (2018). Evidence for intragenic recombination and selective sweep in an effector gene of Phytophthora infestans. Evolutionary applications, 11(8), 1342-1353.

Yin, J., Gu, B., Huang, G., Tian, Y., Quan, J., Lindqvist-Kreuze, H., \& Shan, W. (2017). Conserved RXLR effector genes of Phytophthora infestans expressed at the early stage of potato infection are suppressive to host defense. Frontiers in plant science, 8, 2155.

Yu, X., Tang, J., Wang, Q., Ye, W., Tao, K., Duan, S., . . Zheng, X. (2012). The RxLR effector Avh241 from Phytophthora sojae requires plasma membrane localization to induce plant cell death. New Phytologist, 196(1), 247-260.

Zhang, M., \& Coaker, G. (2017). Harnessing effector-triggered immunity for durable disease resistance. Phytopathology, 107(8), 912-919.

Zheng, X., McLellan, H., Fraiture, M., Liu, X., Boevink, P. C., Gilroy, E. M., . . Birch, P. R. (2014). Functionally redundant RXLR effectors from Phytophthora infestans act at different steps to suppress early flg22-triggered immunity. PLoS Pathog, 10(4), e1004057. 